\title{
Prediksi Klasifikasi Pembangunan Merek Kosmetik Dengan Metode Enbag K-Logres Berdasarkan Keterlibatan Pengguna Facebook
}

\author{
Fajar Sarasati ${ }^{1}$, F. Lia Dwi Cahyanti ${ }^{2}$, Annida Purnamawati ${ }^{3}$, Riyan Latifahul Hasanah ${ }^{4}$ \\ ${ }^{1}$ IImu Komputer, STMIK Nusa Mandiri \\ 2,3Prodi Sistem Informasi, Universitas Bina Sarana Informatika \\ ${ }^{4}$ Prodi Teknologi Komputer, Universitas Bina Sarana Informatika
}

1fajar.fss@nusamandiri.ac.id, ${ }^{2 f l i a . f d c @ b s i . a c . i d, ~}{ }^{3} a n n i d a . n p m @ b s i . a c . i d, ~{ }^{4}$ riyan.rlt@bsi.ac.id

\begin{abstract}
Building a brand new company that starts a business by conducting market research is intended to introduce new products and maintain existing businesses. But the market survey actually requires quite a lot of costs for transportation costs, brochure printing costs, more employee salaries and so forth. Surveys conducted offline also reach a less extensive market, less maximum results and less detail, and require more time. Based on the description above, the researchers conducted a study using Facebook performance metric data that assessed the construction of cosmetics brands using the K-Nearest Neighbor and Logistics Regression (SVM) algorithm by classifying which posts were the most desirable and less desirable by consumers, as well as measuring by the EnBag method KLoGres of the two algorithms to improve the performance of the two proposed algorithms. Bagging technique was chosen because it has the advantage of being able to improve the measurement results and improve the accuracy of classification measurements by combining two or more algorithms. Based on the measurement results of Facebook metric data which assesses the development of cosmetic brands with the K-NN algorithm it gets an accuracy of $68.67 \%$ and a Logistic Regression (SVM) of $72.67 \%$ then the two algorithms are processed using the EnBag K-LoGres method getting an accuracy of $73.91 \%$. Based on the results of measurements with the EnBag KLoGres method the results increased by $1.24 \%$.
\end{abstract}

Keywords: Brand Development, Cosmetics, K-Nearest-Neighbour, Logistic (SVM), EnBag K-Logres

Abstrak: Membangun merek perusahaan yang baru memulai usaha dengan melakukan riset pasar dimaksudkan untuk memperkenalkan produk baru serta mempertahankan usaha yang sudah ada. Namun survei pasar justru membutuhkan biaya yang cukup banyak untuk biaya transportasi, biaya cetak brosur, gaji karyawan lebih banyak dan lain sebagainya. Survei yang dilakukan secara offline juga menjangkau pasar kurang luas, hasil kurang maksimal dan kurang merinci, serta membutuhkan waktu yang lebih lama. Berdasarkan uraian diatas maka peneliti melakukan penelitian dengan memanfaatkan data metrik kinerja facebook yang menilai pembangunan merk kosmetik dengan menggunakan algoritma K-Nearest Neighbourdan Logistic Regreesion (SVM) dengan mengklasifikasikan postingan mana yang paling diminati dan kurang diminati oleh konsumen, serta melakukan pengukuran dengan metode EnBag K-LoGres dari kedua algoritma untuk meningkatkan kinerja kedua algoritma yang diusulkan. Teknik bagging dipilih karena memiliki kelebihan dapat memperbaiki hasil pengukuran serta meningkatkan akurasi dari pengukuran klasifikasi dengan menggabungkan dua atau lebih algoritma. Berdasarkan hasil pengukuran data metrik facebook yang menilai pembangunan merek kosmetik denganalgoritma K-NN memperoleh akurasi sebesar $68.67 \%$ dan Logistic Regression (SVM) sebesar $72.67 \%$ selanjutnya kedua algoritma diproses dengan metode EnBag K-LoGres mendapat akurasi sebesar $73.91 \%$. Berdasarkan hasil pengukuran dengan metode EnBag K-LoGreshasilnya mengalami kenaikan sebesar $1.24 \%$.

Kata kunci: Pembangunan Merek, Kosmetik, K-Nearest Neighbour, Logistic Regression (SVM), EnBag K-LoGres 
This is an open access article distributed under the Creative Commons Attribution License, which permits unrestricted use, distribution, and reproduction in any medium, provided the original work is properly cited. (C2019 by author and IJSE-Indonesian Journal on Software Engineering.

\section{A. PENDAhUluan}

Media sosial menjadi salah satu bukti perkembangan teknologi yang semakin canggih saat ini, jenis konten internet ini memiliki peran penting sebagai alat komunikasi dimana setiap pengguna dapat berbagi informasi, pengetahuan dan saling terhubung. Sosial media merupakan konsep ruang digital dimana setiap pengguna dapat membuat rangkuman profil, mendeskripsikan dirinya untuk berinteraksi dengan orang-orang dari kalangan berbeda, baik dalam lingkungan antar individu maupun dengan perusahaan (Santoso, dkk:2017).

Perkembangan teknologi yang semakin canggih saat ini telah merambah dihampir seluruh lini kehidupan tak terkecuali pada bidang bisnis yang membutuhkan saluran penting untuk menjangkau konsumen dan client.

Berdasarkan hasil survei dari APJII (2016:1) mengungkapkan bahwa ada tiga besar konten internet yang dikonsumsi pengguna, yakni media sosial sebanyak 129,2 juta $(97,7 \%)$, hiburan 128,4 juta $(96,8 \%)$ dan berita 127,9 juta $(96,4 \%)$. Sisanya konten pendidikan 124 juta pengguna, komersial 123,5 juta dan layanan publik 121,5 juta. Terkait media sosial, Facebook yang terbesar dengan 71,6 juta pengguna (54\%). Disusul Instagram dan Youtube, masing-masing dengan 19,9 juta pengguna dan 14,5 juta. Berdasarkan data tersebut maka dapat menjadi potensi yang besar bagi perusahaan untuk membangun merek serta memasarkan produknya dengan memanfaatkan media sosial.

Melihat hasil survei dari APJII tahun 2016 media sosial Facebook menjadi salah satu media sosial yang memiliki potensi besar dalam bidang perekonomian khususnya bisnis, banyaknya pengguna Facebook memiliki dampak langsung untuk meningkatkan nilai perusahaan dan membangun merek perusahaan sehingga secara tidak langsung akan berdampak pada pendapatan perusahaan.

Bagi wanita, produk kosmetik selalu menjadi bagian dari kehidupan sehari-hari, demi mendapatkan dan mempertahankan kecantikan dari waktu ke waktu. Kondisi ini dimanfaatkan betul oleh produsen kosmetik. Jumlah penduduk sekitar 250 juta jiwa menjadikan Indonesia pasar yang menjanjikan bagi perusahaan kosmetik (Briliani et al, 2016:545)

Namun untuk membangun merek produk kosmetik yang banyak diminati sekalipun, perusahaan harus melakukan survei pasar untuk meminimalisir kerugian produksi, karena tidak semua produk diminati oleh konsumen serta banyaknya pesaing sehingga membutuhkan survei pasar mengenai produk mana yang paling diminati dan dibutuhkan oleh pelanggan. Sedangkan untuk melakukan survei pasar perusahaan membutuhkan biaya yang cukup banyak untuk biaya transportasi, biaya cetak brosur, gaji karyawan lebih banyak dan lain sebagainya. Selain itu apabila survei dilakukan secara offline jangkaun pasar kurang luas, hasil kurang maksimal dan kurang merinci, serta membutuhkan waktu yang lebih lama. Media sosial Facebook dipilih karena mempunyai potensi yang besar untuk memasarkan produk mengingat jumlah penggunanya yang masih menempati posisi pertama dari sekian banyak media sosial.

Berdasarkan eksperiment yang dilkukan oleh (Moro et al., 2016) dengan data yang sama menghasilkan metrik kinerja berbasis visualisasi lebih sulit untuk dimodelkan untuk mencapai hasil terbaik, dimana "jangkauan seumur hidup oleh orang-orang yang menyukai halaman". Dengan 37,5\% dan perbedaan lebih dari $10 \%$ berdasarkan interakti terbaik. Dengan demikian prediksi kedua metrik berbasis visualisasi yang dianggap terbaik hanya dinggap pengguna yang menyukai halaman, sehingga kedua metrik murni berbasis visualisasi diprediksi buruk. Maka berdasarkan eksprerimen tersebut peneliti memberikan solusi dengan memanfaatkan dataset metrik kinerja Facebook tahun 2016 untuk dapat dimanfaatkan sebagai acuan untuk mengambil keputusan atau melakukan peningkatan prediksi dalam pembangunan merek dengan menganalisa tingkat keterlibatan konsumen produk kosmetik berdasarkan jumlah dari jumlah komentar, suka dan berbagi pos. Berdasarkan uraian diatas maka peneliti menggunakan algoritma K-Nearest Neighbour dan Logistic Regression (SVM) dengan metode yang telah diadopsi dari metode Ensemble teknik Bagging yang diberinama metode EnBag K-LoGres. Penelitian ini menghasilkan keputusan berdasarkan tingkat akurasi dari data yang telah diolah dan disajikan dalam bentuk kurva ROC. 


\section{B. TINJAUAN PUSTAKA}

\section{Data Mining}

Menurut Afrisawati dalam Maulida (2018:169) menjelaskan bahwa data mining adalah suatu istilah yang digunakan untuk menguraikan penemuan pengetahuan di dalam database. Data mining adalah proses yang menggunakan tenik statistic, matematika, kecerdasan buatan, dan machine learning untuk mengekstraksi dan mengidentifikasi informasi yang bermanfaat dan pengetahuan yang terkait dari berbagai database besar

Menurut ACM dalam Suyanto (2017:1) mengungkapkan bahwa Data mining merupakan gabungan sejumlah disiplin ilmu komputer. Sedangkan menurut Clifton dalam Suyanto (2017:1) mendefinisikan data mining sebagai proses penemuan pola-pola baru dari kumpulan-kumpulan data sangat besar, meliputi metode-metode yang merupakan irisan dari artificial intelligence, machine learning, statistics dan database systems.

Menurut Suyanto (2017:3) menjelaskan bahwa secara umum kegunaan data mining dapat dibagi menjadi dua: deskriptif dan prediktif. Deskriptif berarti data mining digunakan untuk mencari pola-pola yang dapat dipahami manusia yang menjelaskan karakteristik data. Sedangkan prediktif berarti data mining digunakan untuk membentuk sebuah model pengetahuan yang akan digunakan untuk melakukan prediksi.

Menurut Fayyed dkk dalam Suyanto (2017:3) berdasarkan fungsionalitasnya, tugas-tugas data mining bisa dikelompokkan kedalam enam kelompok berikut ini:

1. Klasifikasi (classificationi): men-generalisasi struktur yang diketahui untuk diaplikasikan pada data-data baru. Misalnya, klasifikasi penyakit ke dalam sejumlah jenis, klasifikasi email kedalam spam atau bukan.

2. Klasterisasi (clustering): mengelompokkan data, yang tidak diketahui label kelasnya, kedalam sejumlah kelompok tertentu sesuai dengan ukuran kemiripan.

3. Regresi (regression): menemukan suatu fungsi yang memodelkan data dengan alat (kesalahan prediksi) seminimal mungkin.

4. Deteksi anomali (anomaly detection): mengidentifikasi data yang tidak umum, bisa berupa outlier (pencilan), perubahan atau deviasi yang mungkin sangat penting dan perlu investigasi lebih lanjut.

5. Pembelajaran aturan asosiasi (asociation rule learning) atau pemodelan kebergantungan (dependency modeling): mencari relasi antar variabel.

6. Perangkuman (summarization): menyediakan representasi data yang lebih sederhana, meliputi visualisasi dan pembuatan laporan.

Menurut Mardhiyah \& Yuli dalam Joyendri (2017:77) tahapan data mining ada 6 yaitu: data cleaning, data integration, data selection, data transformation, proses mining dan evaluasi pola.

\section{Knowledge Discovery In Database}

Menurut Ndaumanu dkk dalam Putra dan Wadisman (2018:73) menjelaskan bahwa KDD (Knowledge Discovery In Database) adalah keseluruhan proses non-trivial untuk mencari dan mengidentifikasikan pola (pattern) dalam data, dimana pola yang ditemukan bersifat sah, baru dapat bermanfaat dan dapat dimengerti

Proses KDD menurut Nasari dan Surya dalam Putra dan Wadisman (2018:73) dapat dijelaskan sebagai berikut:

1. Data Selection

Pemilihan (seleksi) data dari sekumpulan data operasional perlu dilakukan sebelum tahap penggalian informasi dalam KDD dimulai. Data hasil seleksi yang akan digunakan untuk proses Data mining disimpan dalam suatu berkas, terpisah dari basis data operasional.

2. Pre- processing atau Cleaning

Sebelum proses Data mining dapat dilaksanakan, perluh dilakukan proses pembersihan pada data yang menjadi fokus KDD. Proses pembersihan mencakup antara lain membuang duplikasi data, memeriksa data yang inkosisten, dan memperbaiki kesalahan pada data, seperti kesalahan cetak (tipografi).

3. Transformation

Coding adalah transformasi pada data yang telah dipilih, sehingga data tersebut sesuai untuk proses Data mining. Proses coding dalam KDD merupakan proses kreatif dan sangat tergantung pada jenis atau pola informasi yang akan dicari dalam basis data. 


\section{Data Mining}

Data mining adalah proses mencari pola atau informasi menarik dalam data terpilih dengan menggunakan teknik atau metode tertentu. Teknik, metode, atau algoritma dalam Data mining sangat bervariasi. Pemilihan metode atau algoritma yang tepat sangat bergantung pada tujuan dan proses KDD secara keseluruhan. Seperti halnya Susanto dan Sudiyatno (2014) meneliti tentang penerapan data mining untuk memprediksi prestasi belajar siswa berdasarkan status sosial ekonomi orang tua, motivasi, kedisiplinan siswa dan prestasi masa lalu dengan algoritma $\mathrm{J} 48$.

5. Interpretation atau Evaluation

Pola informasi yang dihasilkan dari proses Data mining perlu ditampilkan dalam bentuk yang mudah dimengerti oleh pihak yang berkepentingan. Tahap ini merupakan bagian dari proses KDD yang disebut interpretation. Tahap ini mencakup pemeriksaan apakah pola atau informasi yang ditemukan bertentangan dengan fakta atau hipotesis yang ada sebelumnya

Menurut Sembiring, Muhammad Ardiansyah (2016:61) menjelaskan bahwa Data mining juga dapat diartikan sebagai pengekstrakan informasi baru yang diambil dari bongkahan data besar yang membantu dalam pengambilan keputusan.

Tahapan-tahapan pada data mining dapat digambarkan seperti gambar II.1 berikut:

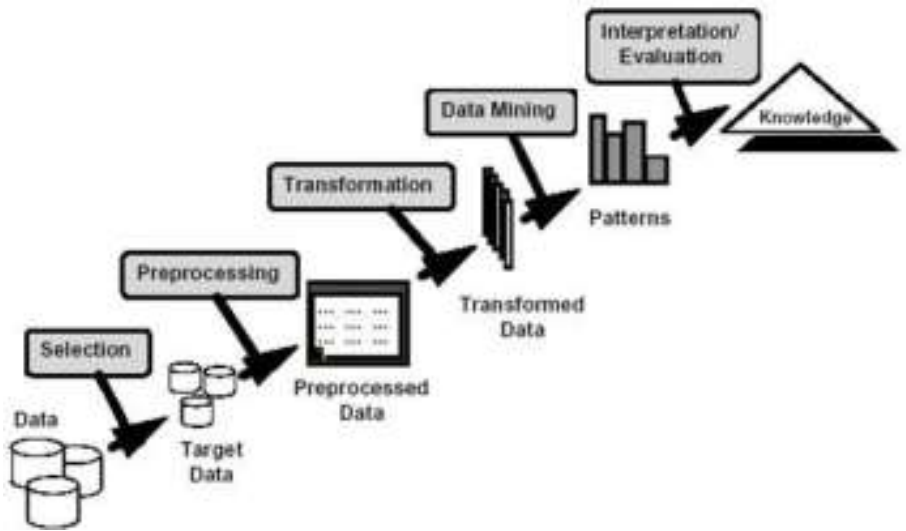

Sumber: (https://dosen.perbanas.id/:2016)

\section{Gambar 1. Tahapan Data Mining}

\section{Classification}

Classification adalah metode yang paling umum pada data minig. Persoalan bisnis seperti Churn Analysis, dan Risk Management biasanya melibatkan metode Classification.

Classification adalah tindakan untuk memberikan kelompok pada setiap keadaaan. Setiap keadaan berisi sekelompok atribut, salah satunya adalah class attribute. Metode ini butuh untuk menemukan sebuah model yang dapat menjelaskan class attribute itu sebagai fungsi dari input attribute.

Yang termasuk dalam Classification Algorithm adalah Decision Trees, Neural Network dan Naives Bayes. (https://www.dosenpendidikan.co.id/metode-data-mining/:2020)

\section{K-Nearest Neighbor}

Algoritma $k$-nearest neighbor ( $\mathrm{k}-\mathrm{NN}$ atau KNN) adalah sebuah metode untuk melakukan klasifikasi terhadap objek berdasarkan data pembelajaran yang jaraknya paling dekat dengan objek tersebut. Ketepatan algoritma k-NN ini sangat dipengaruhi oleh ada atau tidaknya fitur-fitur yang tidak relevan, atau jika bobot fitur tersebut tidak setara dengan relevansinya terhadap klasifikasi. Riset terhadap algoritma ini sebagian besar membahas bagaimana memilih dan memberi bobot terhadap fitur, agar performa klasifikasi lebih baik. KNN juga merupakan contoh teknik lazy learning, yaitu teknik yang menunggu sampai pertanyaan (query) datang agar sama dengan data training. (Wu dalam Dewi, 2016) 


\section{Logistic Regression}

Regresi logistik (Logistic Regression) adalah bagian dari analisis regresi yang digunakan ketika variabel dependen (respon) merupakan variabel dikotomi. Variabel dikotomi biasanya hanya terdiri atas dua nilai (Santosa dalam Dewi, 2016) yang mewakili kemunculan atau tidak adanya suatu kejadian yang biasanya diberi angka 0 atau 1 . Tidak seperti regresi linier biasa, regresi logistik tidak mengasumsikan hubungan antara variabel independen dan dependen secara linier.

Ada beberapa penelitian yang menggunakan komparasi algoritma klasifikasi untuk mengukur akurasi terhadap dataset marketing bank:

1. Could Decision trees Improve the Classification Accuracy and Interpretability of Loan Granting Decision? penelitian yang dilakukan (Zurada,2010). Yang melakukan komparasi dari beberapa metode diantaranya adalah regresi logistik(LR), jaringan saraf $(\mathrm{NN})$, dasar fungsi jaringan saraf radial (RBFNN), SVM, CBR, dan pohon keputusan (DTs). Dari semua model ternyata tingkat klasifikasi akurasi yang mengungguli adalah Decision Trees, DTs tidak hanya mengklasifikasikan lebih baik dari model-model yang lain tapi juga memiliki pengetahuan dalam membentuk aturan yang mudah ditafsirkan, masuk akal dalam menjelaskan tentang alasan penolakan pinjaman.

2. Comparing decision trees with logistic regression for credit risk analysis (Satchidananda \& Simha, 2006). Penelitian ini membandingkan dua model algoritma untuk analisa resiko kredit, yaitu Pohon Keputusan dan Regresi Logistik. Data diambil dari dua bank yang berbeda, kemudian untuk mengelompokkan kasus positif dan negatif maka dilakukan klustering data dengan menggunakan k-means. Hasil analisa dari masing-masing model dikomparasi dan kemudian diukur,kemudian didapatkan bahwa algoritma pohon keputusan mempunyai tingkat akurasi yang tinggi dibandingkan algoritma regresi logistik.

\section{METODE PENELITIAN}

Metode yang diusulkan menggunakan metode Classification dengan algoritma $K$-Nearest Neighbour dan Logistic Regression (SVM) kemudian kedua algoritma diproses menggunakan metode Ensemble dengan teknik Bagging. Pada penelitian ini dataset yang digunakan ialah dataset sekunder dan berisi jumlah analisis sentimen pengguna Facebook pada tahun 2016 yang berisi jumlah komentar, like, share dan atribut lainnya tentang pembelian kosmetik.

Pada penelitian ini dimulai dengan membagi dataset menjadi data training dan data testing menggunakan operator split validation.

Berikut alur sistem yang dapat digambarkan setelah penelitian dilakukan.

\section{Alur Proses Sistem}

Metodologi yang diusulkan peneliti yaitu dengan mengukur data dengan masing-masing algoritma, namun hasilnya kurang bagus sehingga diukur kembali dengan menggabungkan kedua algoritma dengan bantuan metode Ensemble teknik Bagging hingga diperoleh hasil yang lebih bagus dibanding dengan hasil sebelumnya. Pada penelitian ini peneliti menggunakan gabungan algoritma K-NN dan Logistic Regression (SVM) sehingga peneliti menggunakan metode baru yang diberi nama Enbag KLoGres dimana nama tersebut hasil adopsi dari kedua algoritma yang dipakai.

Pada prosesnya metodologi ini menggunakan Operator Multiply yang digunakan pada saat kondisi satu data diproses oleh dua algoritma K-NN dan Logistic Regression (SVM).

Kemudian setelah dilakukan pengukuran dengan menggunakan masing-masing algoritma dan mendapatkan hasil akurasi kurang bagus, maka dilakukan penanganan dengan metode EnBag $\mathrm{K}$ LoGres yang bertujuan untuk meningkatkan akurasi pengklasifikasian dengan menggabungkan pengklasifikasi tunggal. Seperti yang ditampilkan pada gambar dibawah ini: 


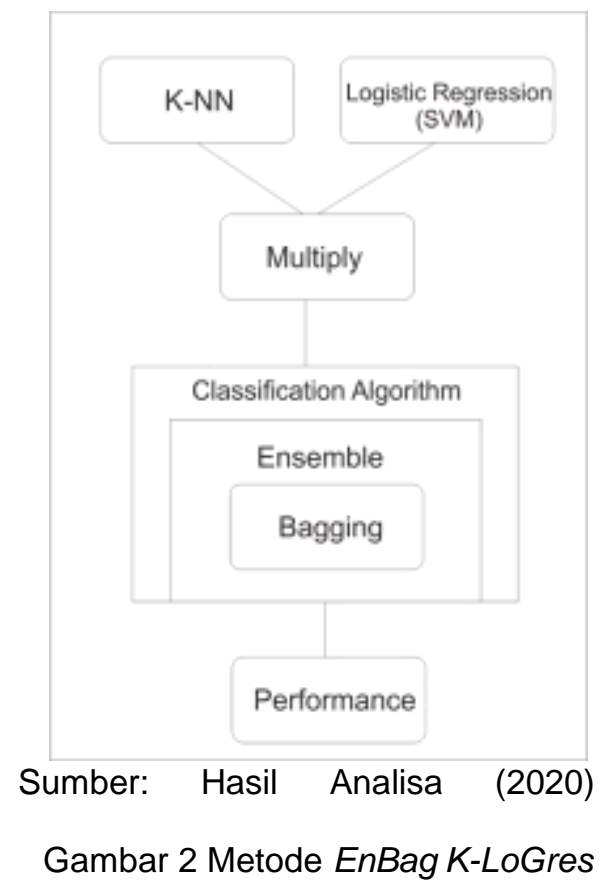

Metode EnBag K-LoGres merupakan hasil gabungan dari metode Classification dengan algoritma K-NN dan Logistic Regression (SVM), keduanya digabungkan menjadi algoritma baru dan diproses dengan operator Multiply yang berfungsi untuk membuat salinan objek pada Rapid Miner. Metode Ensemble untuk mencari solusi prediksi terbaik dibanding algoritma lain, serta menggunakan teknik Bagging yang digunakan meningkatkan stabilitas dan akurasi. Penggabungan kedua algoritma ini bertujuan untuk meningkatkan akurasi pengklasifikasian dengan menggabungkan pengklasifikasi tunggal.

\section{HASIL DAN PEMBAHASAN}

\section{Sumber Data}

Data metrik kinerja Facebook pada tahun 2016 yang terdiri dari 18 atribut diantaranya: Page total likes, Category, Post Month, Post Weekday, Post Hour, Paid, Lifetime Post Total Reach, Lifetime Post Total Impressions, Lifetime Engaged Users, Lifetime Post Consumers, Lifetime Post Consumptions, Lifetime Post Impressions by people who have liked your Page, Lifetime Post reach by people who like your Page, Lifetime People who have liked your Page and engaged with your post, comment, like, share, dan Total Interactions yang berhubungan dengan kinerja Facebook mengenai sentimen pembelian kosmetik yang diperoleh dari https://archive.ics.uci.edu/

\section{Pengolahan Data}

Pada tahap Pre-processing dilakukan pembersihan data dengan melakukan replace missing value yaitu dengan mengisi record yang nilainya kosong dengan bantuan aplikasi Rapid Miner kemudian dimasukkan secara manual pada record yang kosong di Ms Excel. Kemudian diproses dengan metode dan algoritma yang telah diusulkan

\section{Proses}

Pada penelitian ini sebelumnya dataset diukur dengan algoritma K-Nearest Neighbour dan Logistic Regression (SVM) kemudian selanjutnya kedua algoritma dilakukan pengukuran dengan metode Ensemble dengan teknik Bagging secara bersamaan.

Berdasarkan penerapan model yang diusulkan diperoleh pengukuran seperti ditunjukkan pada Tabel 4.1 berikut: 
Tabel 1 Hasil Pengukuran Kinerja Model

\begin{tabular}{|l|c|c|c|l|}
\hline \multicolumn{1}{|c|}{ Model } & Accuracy & AUC & Recall & Pressision \\
\hline K-NN Regression & $68.67 \%$ & 0.602 & $11.90 \%$ & $33.33 \%$ \\
\hline $\begin{array}{l}\text { Logistic } \\
\text { (SVM) }\end{array}$ & $72.67 \%$ & 0.570 & $2.38 \%$ & $100.00 \%$ \\
\hline EnBag K-Logres & $73.91 \%$ & 0.584 & $4.00 \%$ & $100.00 \%$ \\
\hline
\end{tabular}

Sumber: Hasil Analisa (2020)

a. Hasil AUC Pengukuran Kinerja Model

Hasil pengukuran dari masing-masing algoritma beserta hasil penggabungan dari kedua algoritma yang diproses dengan menggunakan metode EnBag K-LoGres disajikan dalam bentuk kurva Receiver Operating Characteristic $(R O C)$ dibawah ini:

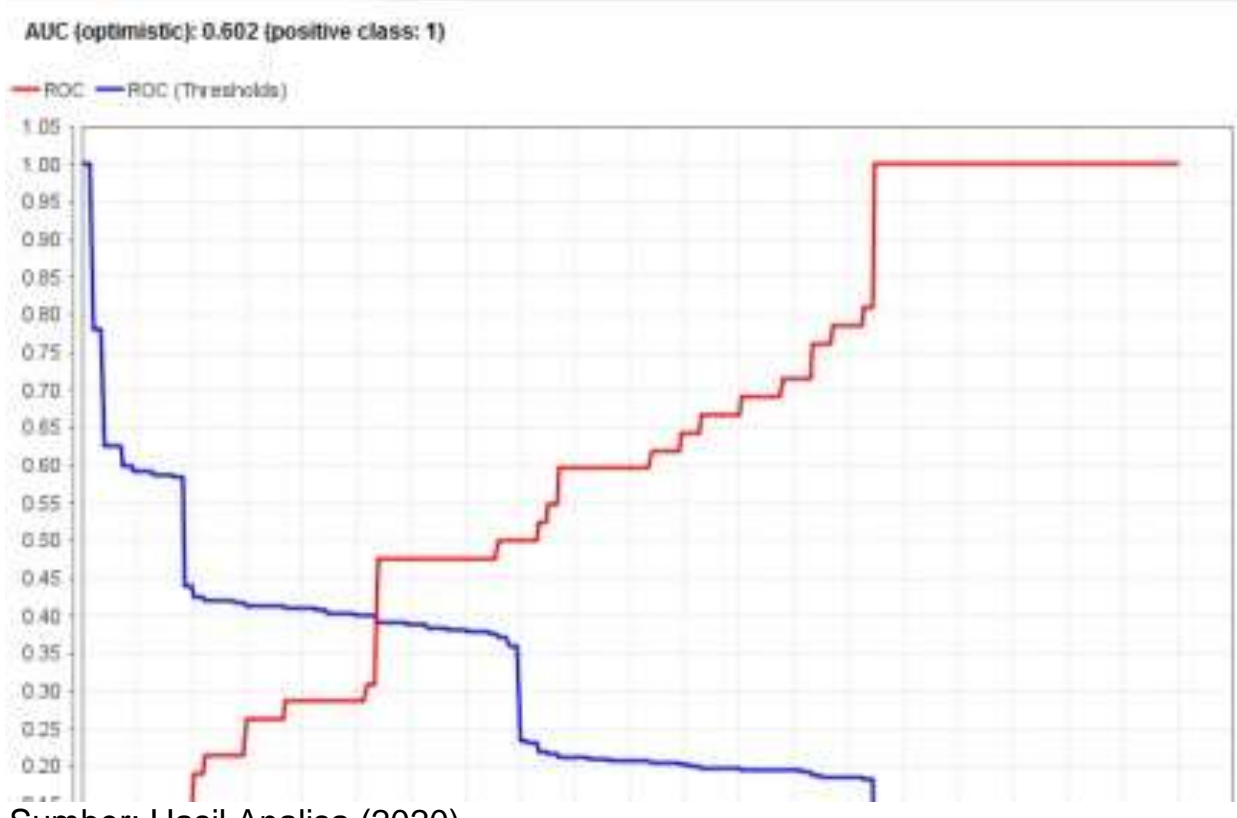

Sumber: Hasil Analisa (2020)

Gambar 3 Hasil Pengukuran AUC Algoritma K-NN

Pada kurva ROC hasil pengukuran algoritma K-NN menunjukkan bahwa jarak antara True Positif Rate dan False Positive Rate berdekatan sehigga Tresholdnya kurang bagus. 


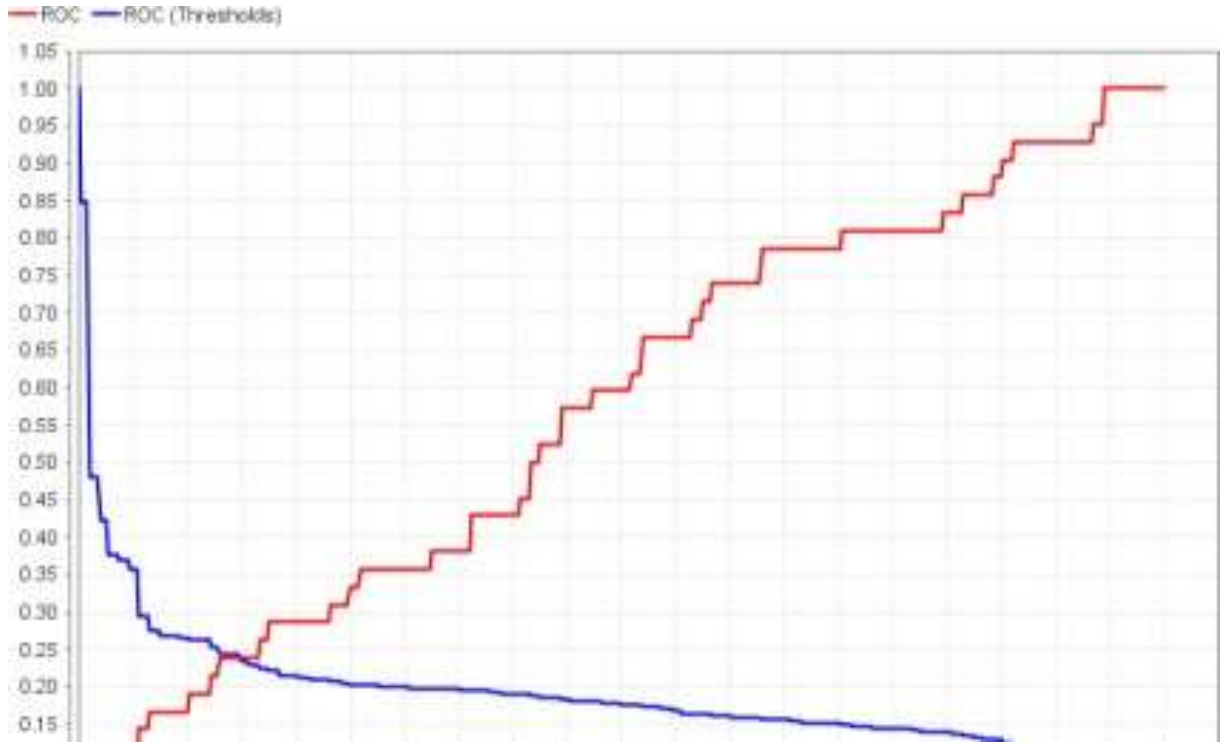

Sumber: Hasil Analisa (2020)

Gambar 4 Hasil Pengukuran AUC dengan Algoritma Logistic Regression (SVM)

Pada kurva ROC hasil pengukuran algoritma Logistic Regression (SVM) menunjukkan bahwa jarak antara True Positif Rate dan False Positive Rate lebih jauh dibanding dengan algoritma K-NN sehingga tresholdnya lebih bagus dari pada Treshold K-NN .

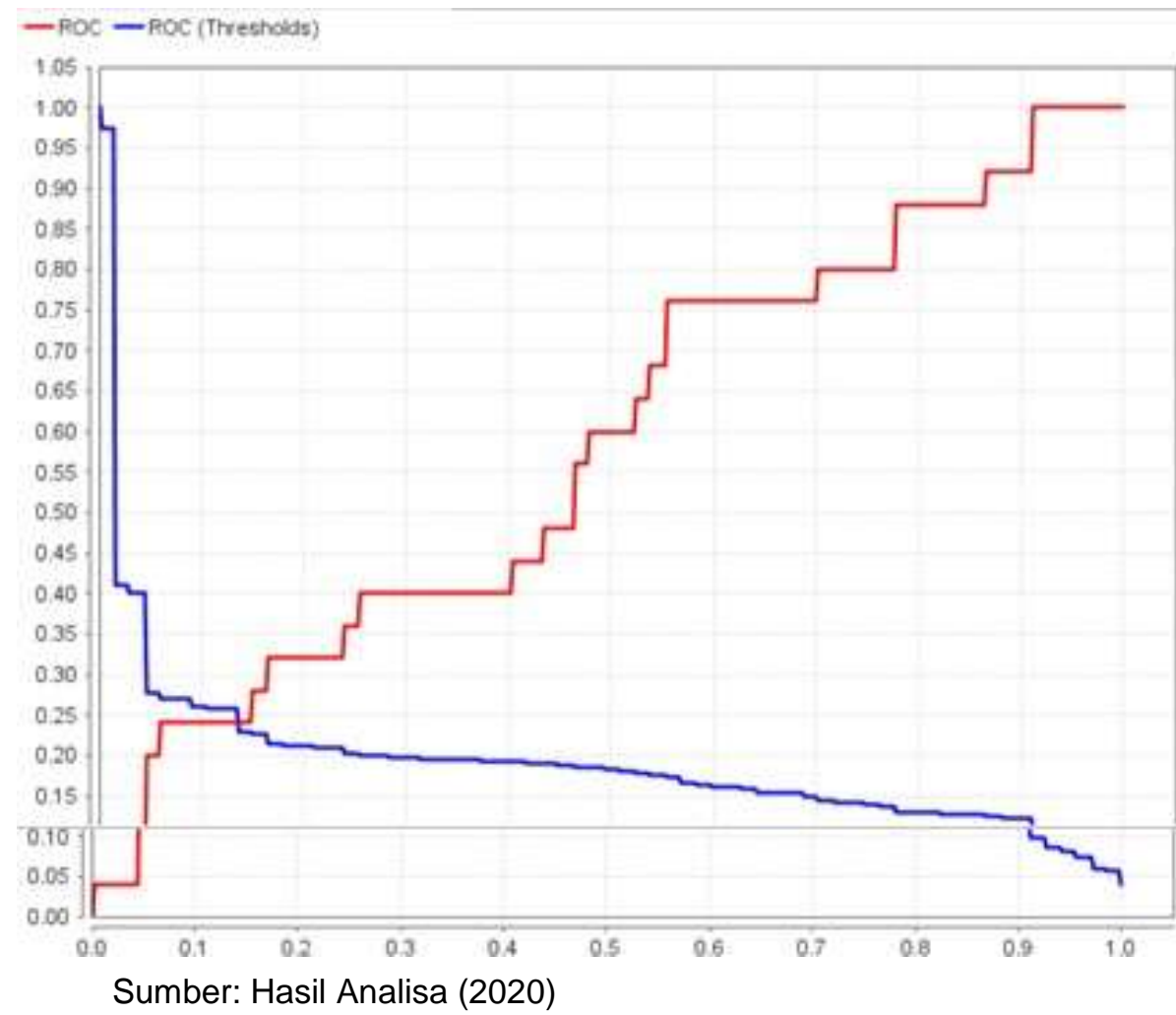

Gambar 5 Hasil Pengukuran AUC dengan Metode EnBag K-LoGres

Pada kurva ROC hasil pengukuran dengan metode EnBag K-LoGres menunjukkan bahwa jarak antara True Positif Rate dan False Positive Rate lebih lebar dari algoritma Logistic 
Regression (SVM) sehigga tresholdnya lebih bagus dibanding kedua algoritma sebelumnya. Berdasarkan keterangan kurva ROC dapat dijelaskan sebagai berikut, dimana Garis warna biru menunjukkan ROC (True Positive Rate) dan Garis warna merah menunjukkan ROC (False Positive Rate)

Maka semakin tinggi True Positive Rate maka semakin kecil False Positive Rate maka Tresholdnya semakin bagus.

\section{E. KESIMPULAN}

Berdasarkan hasil pengukuran dari 2 algoritma yang diusulkan tersebut maka hasilnya mengalami kenaikansebesar $4.00 \%$ dan setelah diproses dengan teknik Bagging kedua algoritma tersebut yaitu K-NN dan Logistic Regression (SVM), maka hasilnya mengalami kenaikan sebesar $1.24 \%$. Sehingga berdasarkan hasil pengukuran yang telah diketahui, hasil penerapan metode Ensemble dengan teknik Bagging pada dataset Metrik Facebook pengguna kosmetik dapat ditarik kesimpulan bahwa metode Ensemble dengan metode EnBag K-LoGres dapat meningkatkan nilai Accuracy dan Pression yang dihasilkan.

\section{F. REFERENSI}

Anbe, S., \& Kobayashi, I. (2014). An approach to category classification of cosmetics reviews based on brand names. 2014 Joint 7th International Conference on Soft Computing and Intelligent Systems, SCIS 2014 and 15th International Symposium on Advanced Intelligent Systems, ISIS 2014, 971975. https://doi.org/10.1109/SCIS-ISIS.2014.7044788

Arfi Joyendri. 2017. Strategi Customer Relationship Management Untuk Meningkatkan Loyalitas Pelanggan Dan Volume Penjualan Menggunakan Teknik Clustering K-Means. Telemat. - J. Inform. Telekomun. Komputasi Elektron. dan Ind. 14: 75-82.

BRILIANI, RIZKA ASRI et al. (2016). Analisis Kecenderungan Pemilihan Kosmetik Wanita Di Kalangan Mahasiswi Jurusan Statistika Universitas Diponegoro Menggunakan Biplot Komponen Utama. None, 5(3), 545-551.

Dewi S. 2016. Pada Prediksi Keberhasilan Pemasaran Produk Layanan Perbankan. Techno Nusa Mandiri XIII: 60-66.

Dosen Pendidikan 3.2020. Metode Data Mining. https://www.dosenpendidikan.co.id/metode-datamining/ (Diakses pada 05 Mei 2020)

Hapsari, Y., Fikri Hidayattullah, M., Dairoh, D., \& Khambali, M. (2018). Opinion Mining Terhadap Toko Online Di Media Sosial Menggunakan Algoritma Naïve Bayes (Studi Kasus: Akun Facebook Dugal Delivry). Jurnal Informatika: Jurnal Pengembangan IT, 3(2), 233-236. https://doi.org/10.30591/jpit.v3i2.919

Hermawanti, L., \& Safriandono, A. (2016). Penggabungan Algoritma Forward Selection Dan K-Nearest Neighbor Untuk Mendiagnosis Penyakit Diabetes Di Kota Semarang. Jurnal Momentum UNWAHAS, 12(2), 138462. https://doi.org/10.36499/jim.v12i2.1631

Indonesia Internet Service Provider Association. 2016. Edisi 05 November 2016. Jakarta: APJII

Kristiyanti, D. A., \& Wahyudi, M. (2017). Feature selection based on Genetic algorithm, particle swarm optimization and principal component analysis for opinion mining cosmetic product review. 2017 5th International Conference on Cyber and IT Service Management, CITSM 2017. https://doi.org/10.1109/CITSM.2017.8089278

Luqyana, W. A., Cholissodin, I., \& Perdana, R. S. (2018). Analisis Sentimen Cyberbullying Pada Komentar Instagram dengan Metode Klasifikasi Support Vector Machine. Jurnal Pengembangan Teknologi Informasi Dan Ilmu Komputer (J-PTIIK) Universitas Brawijaya, 2(11), 4704-4713.

Maulida L. 2018. Kunjungan Wisatawan Ke Objek Wisata Unggulan Di Prov . Dki Jakarta Dengan KMeans. J. Inform. Sunan Kalijaga 2: 167-174.

Moro S, Rita P, Vala B. 2016. Predicting social media performance metrics and evaluation of the impact on brand building: A data mining approach. J. Bus. Res. 69: 3341-3351.

Muhammad Ardiansyah Sembiring. 2016. PENERAPAN METODE DECISSION TREE ALGORITMA C45 UNTUK MEMPREDIKSI HASIL BELAJAR MAHASISWA BERDASARKAN RIWAYAT

ejournal.bsi.ac.id/ejurnal/index.php/ijse Copyright (C) Universitas Bina Sarana Informatika 
AKADEMIK. JURTEKSI (JURNAL Teknol. DAN Sist. INFORMASI).

Oktanisa, I., \& Supianto, A. A. (2018). Perbandingan Teknik Klasifikasi Dalam Data Mining Untuk Bank a Comparison of Classification Techniques in Data Mining for. Teknologi Informasi Dan Ilmu Komputer, 5(5), 567-576. https://doi.org/10.25126/jtiik20185958

Perbasnas Institut. 2016. Sarana Tukar Menukar Informasi dan Pemikiran Dosen.

https://dosen.perbanas.id/apa-itu-data-mining/ (Diakses tanggal 03 Juni 2020).

Randi Rian Putra CW. 2018. IMPLEMENTASI DATA MINING PEMILIHAN PELANGGAN POTENSIAL MENGGUNAKAN ALGORITMA K-MEANS IMPLEMENTATION OF DATA MINING FOR POTENTIAL CUSTOMER SELECTION USING K-MEANS ALGORITHM. J.

Inf. Technol. Comput. Sci. 1: 72-77.

Satvika, G. A. J., Nasution, S. M., \& Nugrahaeni, R. A. (2018). Determination of the Best Vehicle Pathway with Classification of Data Mining Twitter using K-Nearest Neighbor. 2018 International Conference on Information Technology Systems and Innovation, ICITSI 2018 - Proceedings, 72-76. https://doi.org/10.1109/ICITSI.2018.8695947

Suyanto. (2017). Data Mining Untuk Klasifikasi dan Klasterisasi Data. Bandung: Informatika

UC Irvine Machine Learning Repository. 2016. Facebook Metrics, [online] Tersedia di:

$<$ https://archive.ics.uci.edu/>[Diakses 2 Oktober 2019] 